\title{
VIEWPOINT
}

\section{Publicatus Interruptus: An Endemic Syndrome Disabling Research and Researchers}

\author{
William R. Phillips, MD, MPH ${ }^{1,2}$ (D) \\ J Gen Intern Med 37(7):1774-6 \\ DOI: $10.1007 / \mathrm{s} 11606-021-07291-6$ \\ (c) The Author(s) under exclusive licence to Society of General Internal \\ Medicine 2021
}

'Department of Family Medicine, University of Washington, Seattle, WA, USA; ${ }^{2}$ Edmonds, USA.

\section{INTRODUCTION}

This report offers a new formulation of an old problem prevalent across academia and identifies it as a distinct diagnostic entity: publicatus interruptus. Publicatus interruptus (PI) is the premature withdrawal of a research report interrupting the act of submitting, revising, and resubmitting before the climax of publication and dissemination of results. PI is a common and potentially disabling condition contributing to failed academic careers, research waste, and lost scientific opportunities.

Novice authors are often awkward in their attempts to establish the rhythm of submit, revise, and resubmit. Even when the editor offers an opportunity to revise and resubmit, inexperience and performance anxiety can lead new authors to pull out of the publication process prematurely. The resulting failure to consummate the author-editor relationship sadly wastes the investigator's precious submission. That seed of new knowledge is spilled and with it the conception of new theories, the gestation of innovative paradigms, and the birth of advancements in science and medicine. Seminal ideas can be lost, and opportunities to reproduce findings forfeited.

\section{HISTORICAL BACKGROUND}

Even the pioneers of medicine failed to publish all their important work. Manuscripts of Hippocrates, Galen, and Paracelsus are lost. Semmelweis and Pasteur faced early rejection. Darwin hesitated for 20 years before publishing the most important work in the history of life sciences. Nature rejected Hans Krebs Nobel Prize-winning report of the discovery of his eponymous cycle. Who knows what discoveries remain unpublished?

Prior presentations: None

Received September 6, 2021

Accepted November 17, 2021

Published online January 3, 2022

\section{PATHOPHYSIOLOGY}

The mechanism of scientific publication requires conjugated steps in a dance of submission, review, rejection, revision, and resubmission. Almost all researchers experience rejection of their work amidst the stiff competition at major medical journals. It may be outright rejection, but often the rejection comes with the opportunity to revise and submit. The author might regard this as a personal failure to meet rigid criteria and squander the opportunity for revision and publication. Premature withdrawal from the back-and-forth process of review and revision prevents the dissemination of study findings. The author's precious results may never reach the fertile ground of receptive readers. Worse than misconception is no conception at all.

\section{CLINICAL PRESENTATION AND COURSE}

Acute PI is the failure to consummate the publication process with one research report. It is common and generally resolves after several successful encounters. Recurrent PI is premature withdrawal of multiple manuscripts over time. Both types can resolve with later revision and acceptance or can go on to become refractory with persistent failure to publish study reports.

Diagnosis relies on clinical observation and patient selfreport. Excess emotional reaction to manuscript rejection is the most common early indicator of PI. Exaggerated hostility to reviewer comments is a strongly suggestive sign, as is premature exasperation.

Onset of PI may be preceded by a related condition, ManuScript Rejection sYndrome (MiSeRY). ${ }^{1}$

PI often follows experiences of rejectile dysfunction, a closely related syndrome to be described in a separate report (still in revision). Maintenance of adequate reflection is essential for successful penetration of the black box of the editorial process. Both conditions are related to performance anxiety, fear of rejection, a sense of shame, and feelings of isolation and despair.

A bottom desk drawer full of pending manuscripts is a critical red flag for the diagnosis of PI.

Out of sight - out of mind. Other works always arise to fill the void left by disappointment.

If left untreated, PI has a poor prognosis. Each episode diminishes intellectual arousal and impairs scientific 
productivity. Without intervention, PI can lead ardent investigators to abandon research, leading to both lost data and lost careers

\section{EPIDEMIOLOGY}

Researchers at all levels of experience face rejection and can suffer from PI. The major cause of failure to publish is failure to submit ${ }^{2}$ and resubmit.

Researchers at increased risk include early-career academics, women, underrepresented minorities, ${ }^{3}$ communitybased clinicians, and patient partners.

\section{TREATMENT}

Initial treatment for PI is reassurance to ameliorate any sense of shame or inadequacy. The goal is to accept rejection without dejection, enhance resilience, and improve coping skills. Guidance from a trusted colleague or mentor is a valuable adjunct. ${ }^{4}$ Education helps new researchers understand that initial rejection is the usual experience for even polished reports of outstanding research.

One imaginative strategy is to respond to editors' rejection letters with an author's rejection of rejection letters. ${ }^{5}$

\section{PREVENTION}

The best way to prevent PI is to prevent rejection, though expecting fulfillment with every submission is unrealistic. Authors should submit their best work to the journal best suited to the research question and implications. Editorial acceptance is a match-and-mate process. Authors desire production; editors respond with reproduction.

Success in research requires mentoring and specific training in the process of publication, including realistic expectations, effective strategies, and specific techniques to overcome barriers to publication. Even senior investigators need colleagues to counsel perseverance, provide feedback, and suggest revisions.

It is essential to budget time and resources for multiple rounds of revision and resubmission. Consummation of successful relationships requires protected quality time. Continued support is crucial for success over the long game of publication.

Teams must establish clear expectations about authorship and control of data. Take special care with senior authors, junior authors, and trainees to prevent problems around retirement, graduation, and moves. The lifespan of a research report-from submission to final publication - can outlast degree programs, jobs, and even careers.

\section{DISCUSSION}

We must recognize that some research is poorly conceived, designed, conducted, and reported. Nevertheless, most of it can find its way into print. ${ }^{6}$ Journal editors bear responsibility to their readers and scientific communities to help minimize the waste of flawed science.

Sometimes early rejection helps investigators refocus their energies along more productive lines. Thoughtful reviewers can help even a pro create a better report of their valuable study.

Fortunately, initial rejection is not a reliable sign of failed research and should not be considered the end of the path to publication. Across disciplines and specialties, most published articles were initially rejected, and most rejected articles are eventually published. ${ }^{7}$ Despite our reliance upon the tradition of peer review, it is unclear whether it aids the selection or revision of study reports.

Future work should focus on improving researcher training and mentoring ${ }^{4}$ to build effective skills to write and revise quality research reports. We also need better mechanisms for peer review and new ways to assess the quality of research. Finally, evolving methods of disseminating research findings may improve treatment and prevention of PI.

\section{CONCLUSION}

PI is a common and costly condition. With no specific cure, prevention, education, and management are the best available strategies. We can all contribute by recognizing the signs of PI in ourselves, trainees, and professional colleagues. Control of PI can help improve the dissemination of quality research, the advancement of science, and improvements in policy, patient care, and population health.

\section{Acknowledgements:}

Contributors: Many thanks to John Frey, MD, for his penetrating critique of early drafts of this work.

Declarations: The author has no financial or other conflicts of interest in connection with this work but discloses that he has personally suffered from the condition described in this report. No patients or members of the public were involved in the design, conduct, reporting, or dissemination plans of this work.

Corresponding Author: William R. Phillips, MD, MPH; Edmonds, USA (e-mail: wphllps@uw.edu).

Funders None

\section{REFERENCES}

1. Han HC, Koshy AN, Lin T, et al. Predictors of manuscript rejection syndrome (misery): a cohort study. Med J Aust 2019;211(11):511-513. https://doi.org/10.5694/mja2.50414.

2. Song F, Loke Y, Hooper L. Why Are medical and health-related studies not being published? A systematic review of reasons given by investigators. 
PLoS One 2014;15;9(10):e110418. https://doi.org/10.1371/journal.pone. 0110418.

3. Guillaume R, Cisneros J, Martinez E. Manuscript rejection and shame resilience in early career faculty of color: Vignettes on coping and overcoming. Taboo: The Journal of Culture and Education. 2020;19(5).https://digitalscholarship.unlv.edu/taboo/vol19/iss5/3

4. Phillips WR. Pursuing personal passion: learner-centered research mentoring. Fam Med 2018; 50:(7)41-46. https://doi.org/10.22454/ FamMed.2018.952474

5. Chapman C, Slade T. Rejection of rejection: A novel approach to overcoming barriers to publication. BMJ. 2015;14:351:h6326. https:// doi.org/10.1136/bmj.h6326.
6. Oosterhaven J. Too many journals? towards a theory of repeated rejections and ultimate acceptance. Scientometrics. 2015;103(1):261-265. https:// doi.org/10.1007/s11192-015-1527-4.

7. Siler K, Lee K, Bero L. Measuring the effectiveness of scientific gatekeeping. Proc Natl Acad Sci USA 2015 ;112(2):360-5. https://doi.org/10.1073/ pnas. 1418218112.

Publisher's Note: Springer Nature remains neutral with regard to jurisdictional claims in published maps and institutional affiliations. 